\title{
Evaluation of the surgeon's workplace in elective procedures: a descriptive study in two Brazilian public hospitals
}

\begin{abstract}
The surgeon is exposed to ergonomic constraints (physical and mental) that may influence on his health from aspects related to physical posture during work to psychological problems arising from the management conditions in the operating room settings. This study evaluates the working conditions during elective surgeries in two Brazilian Public Hospitals. Field observations and a questionnaire were performed. The results indicated dissatisfaction and risks regarding the discomfort/pain, Physical/Environmental, Organizational/Management, and Psychosocial factors.
\end{abstract}

Keywords: ergonomics, operating room, elective surgeries
Volume 8 Issue 5 - 202I

\author{
Francisca Miranda de Araújo,' Raimundo \\ Lopes Diniz, ${ }^{2}$ Ana Hélia de Lima Sardinha, ${ }^{3}$ \\ Rubenio Barros ${ }^{4}$ \\ 'M.Sc. in Environment and Health, Federal University of \\ Maranhão, Brazil \\ ${ }^{2}$ D.Sc. in Industrial Engineering, Post Graduation Program in \\ Design, Federal University of Maranhão, Brazil \\ ${ }^{3}$ D.Sc. in Pedagogy Sciences, Federal University of Maranhão, \\ Brazil \\ ${ }^{4} \mathrm{BS}$. in Design, Federal University of Maranhão, Brazil
}

Correspondence: Raimundo Lopes Diniz, D.Sc. in Industrial Engineering, Post Graduation Program in Design, Federal University of Maranhão, Brazil, Email rl.diniz@ufma.br

Received: April |3, 2021 | Published: October 20, 202 |

\section{Introduction}

Human Factors and Ergonomics (HFE) as a scientific discipline has been crucial to eliminate hazards that contribute to patient falls and that can interfere negatively on the quality of care, through the production knowledge aiming to reduce or mitigate medication errors, redesigning health care systems and processes. ${ }^{1,2}$

At this point, HFE is also important to Operating Room (OR) procedures. Such procedures are expensive, can result in errors or delays in surgical treatments if not properly performed and may even have a substantial impact on patient's safety. Furthermore, surgery skills require both mental and physical workloads, considering the high level of demands regarding intellectual and cognitive preparation, fine motor and physical endurance, as well as an efficient and completely controlled workplace. ${ }^{3}$

The literature review has been relating HFE to OR theater and they make up a growing body of scientific knowledge. ${ }^{4}$ The OR has a complex set of team dynamics and multidisciplinary staff that have to have harmonic and coordinated procedures. These characteristics can provide high-stress, suboptimal communication, clashing motivations, errors arising from the physical and mental workload, besides substandard environmental factors. ${ }^{4}$ In general, OR has important complex tasks directed to safety and effective treatment, a scenario that is involved with a high-risk that can be minimized by task management and HFE intervention. ${ }^{5}$ It can be stated that surgery conditions expose surgeons to high physical, cognitive, and psychosocial demands and more research is needed to understand in details all relationships between surgeon and surgery. ${ }^{6,7}$

For the medical surgeon, this way of working is particularly detrimental considering that surgical practice requires a high level of intellectual preparation, an efficient and controlled working space, clear motor skills, physical endurance and problem/emergency solving skills. Surgeons perform quite exhausting tasks on their muscular, physiological, and psychological functions for the long duration of most surgeries. The degree of skills required for their execution and the standing posture that is indispensable during most surgical interventions, submit these professionals to static postures for prolonged periods, with complex sequential and repetitive maneuvers through their upper limbs, which also involve movements of the lower limbs. This can cause problems such as muscle fatigue, pain in the legs, back, wrists, neck, shoulders and consequent ergonomic constraints, which can lead to deficiencies in work performance, operational neglect, and illness. ${ }^{6}$ Ergonomic constraints are the situations of discomfort and limitations that prevent an ideal condition. Ergonomic constraints can be physical or mental and can be imposed on the worker by the operational, organizational, physical and spatial environment. $^{8}$

Taking into account the above considerations, the main goal of this article was to evaluate the surgeon work conditions in two public hospitals in Brazil. The subject of the research is only elective procedures, such as cholecystectomy. Field observations were performed and a questionnaire was applied among surgeons. The objective of this study was to evaluate the working conditions of the surgeon during elective surgeries in two public hospitals in São Luis-MA (referred to herein as Hospital A and Hospital B, for the purpose of preservation of their identities), seeking to understand the relationships between the possible ergonomic demands (physical, mental and / or emotional) that can exist in the surgical centers and be imposed on these professionals generating imbalances on their work and health. Environmental conditions, work organization and some aspects of the physical conditions of these workers will be presented.

\section{Surgical centers in Brazilian hospitals}

Work as a category has become one of the most important and investigated dimensions in the sphere of human life nowadays. In this way, investigating issues related to the work-individual-illness triad brings into light the importance of recognizing not only the appearance 
of organic problems, the so-called Occupational Related Diseases, but at the same time, the need for discussions about the subjectivity of the worker involved. ${ }^{9}$

Due to its particularities and characteristics, the surgical center constitutes one of the most complex units of a hospital, as a result of the equipment and technologies used, the intrinsic variation of its main processes, the complicated logistics to support its operation and, mainly, the risk of death associated with the procedures performed there. In its routine of operation, several processes and sub-processes are executed, directly or indirectly connected to the production of surgeries, both in the operating room environment itself and in other sectors related to it. ${ }^{10,11}$

The good performance of a surgical center is directly related to the quality of its own processes and to the processes of the services that support it, as a result of a combination of physical facilities, technology and adequate equipment, operated by skilled manpower and in a constant process of improvement. In operating rooms (Figure 1) a range of equipment competes for occupying a considerable part of the physical space and their distribution is an important factor for the safety of patients and the whole team. In this environment is developed a work by the multidisciplinary team, composed of individuals with different backgrounds and abilities, where it exposes a high degree of risk to the patient and the team itself. Each member of the team acts with certain functional, ethical and legal responsibilities for the execution of the procedures. Their functions are organized by establishing cooperative and interdependent relationships, orienting their activities towards established goals and using their knowledge and techniques to perform the required tasks. The main activity performed here is the anesthetic-surgical act, in which directly and indirectly involves the entire team of physicians (surgeons and anesthesiologists), nurses, nursing assistants and/or technicians, residents, trainees of nursing and medicine, among others. ${ }^{12}$

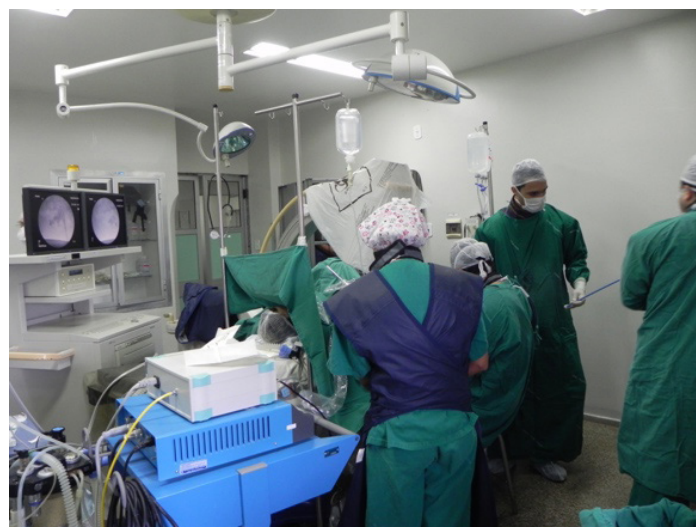

Figure I Example of Operating room from a Public Hospital in Brazil (Araújo, 20|4).

The nature of this work is considered as a source of tension for all members of the team, highlighting the tensions arising from environmental aspects - induced by physical, chemical and biological agents; feeling of isolation; closed environment where care with asepsis is rigorous; and communication problems that generate wear and tear on interpersonal relationships among team members. The anesthetic-surgical procedures, although necessary for patients' treatment, are extremely invasive and impart certain aggressiveness that generates tensions at the conscious or unconscious level. The work is physically tiring, the surgical team works continuously in the standing posture, with no pauses or conditions to rest for long periods, which may result in a decrease in visual perception and auditory vigilance. $^{12}$

For Duarte et al., ${ }^{13}$ regardless of the complexity, surgical centers are environments where there are risks for surgeons to a greater or lesser degree. The risk is external and most of the time it is inherent in work. From the epidemiological point of view, the risk, with effect on health from exposure to agents considered aggressors, can be calculated from the number of cases of manifested diseases or mortality.

In the case of health workers, especially doctors, discussing the working conditions becomes quite important due to the labor characteristics of these professionals who deal with the most valuable good, the human life, and where doctors themselves are exposed to several risks in the hospital environment such as work shifts that have harmful effects on human health, direct contact with patients that leaves the professional vulnerable to contamination and besides, the cases of depression that are common among these workers.

\section{Ergonomic intervention and the work of surgeons}

Since Frank Gilbreth's studies related to surgeons' work, evidenced during the early part of 20th century, there are many efforts at objectively studying surgical operations. According to Berguer, the state of the art that corresponds the OR procedures is so curious because many of the mental and physical demands are similar to industrial and military tasks. Most of the studies have been appointing surgeons' progressive postural changes caused by OR activities and workload. This context may reduce the professional practice lifetime and impair the quality of life. On the other hand, professional organizations linked to surgery are asked to act on the optimization of the workplace conditions in the OR aiming to improve quality and efficiency. ${ }^{14}$ And it seems like that during the last ten years, the Ergonomic intervention concerning the work of surgeons' scenario has been describing the same issues.

Matern and Koneczny ${ }^{141}$ evaluated the surgeons' workplace conditions in ORs from German hospitals. They have performed a survey studying 425 surgeons and their workplaces, where the results showed elementary ergonomic deficiencies regarding Spatial conditions, Equipment arrangement in the OR, Working posture and, Individual preferences. Authors concluded that $97 \%$ of the surveyed surgeons recognize the importance of ergonomic improvements in the operating room.

van Det et al., ${ }^{15}$ investigated the monitor positioning in Minimally Invasive Surgery (MIS) as an important ergonomic component during MIS. Their findings appointed out a relevant proximity between the configuration of the monitors and the occupational posture of the surgeons: the monitor should be straight in front of each surgeon and aligned with the forearm-instrument motor axis to avoid axial rotation of the spine and, in the sagittal plane, the monitor should be positioned lower than eye level to avoid neck extension. A series of studies are being conducted in Hong Kong, to examine the real-time movements and electromyography of surgeons in the operating room during open and endoscopic procedures because mechanical stress has clinical repercussions, resulting in effects on connective tissue, muscle, and in the joints. The lack of body alignment during surgical procedures can alter the distribution of load and pressure on the articular surfaces, contributing to joint degeneration and inadequate muscular tensions. ${ }^{16}$

Xiao et al., ${ }^{17}$ evaluated occupational posture during laparoscopic surgery training. The results suggest that under the reference of optimal ergonomic conditions it is held much more the adoption of the neutral posture, according to the current ergonomic training 
guidelines. The authors' considerations indicated that surgeons trained under ergonomic setting may have a less joint excursion, experience less discomfort and have better task performance.

Physical factors and their associations with Work-related Musculoskeletal Symptoms (WMS) among surgeons in laparoscopic procedures also were examined by Esposito et al. ${ }^{18}$ The results indicated that the surgical procedures performed had a strong association with WMS and suggested that novice surgeons have less pain than senior surgeons. Also, the shoulder was the main corporal segment referred by the majority of surgeons that presented WMS.

Lee et al., ${ }^{19}$ have been investigating physical and mental workloads differences between robotic and laparoscopic surgeries demands. Authors'findings presented that both robotic and laparoscopic surgeries demonstrated levels of physical and mental workloads, but less in robotic. Another study, conducted by Aitchison et al. ${ }^{20}$ in Australia, identified extreme angles related to motion and biomechanical movements during laparoscopic gynecologic procedures. Shoulder abduction angles were the most extreme.

Aghilinejad et al., ${ }^{21}$ conducted a descriptive-analytic study on 81 surgeons in a hospital in Tehran. It was evaluated the prevalence of musculoskeletal symptoms among surgeons using the Nordic Questionnaire and the Workplace Ergonomic Risk Assessment method (WERA). As results, the study presented risk factors related to the musculoskeletal system, mainly on the neck, back, shoulder, waist, wrists, and arms in 3 types of surgery: laparoscopy, microsurgery, and open surgery.

The Table 1 presents a research chart found on the subject. In general, the most studied ergonomic constraints were postural and mental, but without establishing a relation of these constraints with the environmental and organizational working conditions.

Table I Literature review on ergonomic constraints about general elective surgeon's work 2003-20I7

\begin{tabular}{|c|c|c|c|}
\hline AUTHORS/YEAR & TYPE OF SURGERY & $\begin{array}{l}\text { ERGONOMIC } \\
\text { CONSTRAINTS } \\
\text { STUDIED }\end{array}$ & REGION STATE/COUNTRY \\
\hline Diniz, 2003 & General Elective & Postural and Mental & Porto Alegre//Brazil \\
\hline Matern \& Koneczny, 2007 & Several kinds & All fields & Germany \\
\hline Szeto et al., 2009 & General Elective & Postural & Hong Kong/China \\
\hline van Det et al., 2009 & Laparoscopy & Postural & Amsterdam/The Netherlands \\
\hline Szeto et al., 2010 & General Elective & Postural & Boston/USA \\
\hline Foss et al., 2012 & General Elective & Postural & São Paulo/Brazil \\
\hline Xiao et al., 2012 & Laparoscopy & Postural & Delft/Netherlands \\
\hline Esposito et al., 2013 & Laparoscopy & Postural & Naples, Italy \\
\hline Abdalla et al., 2013 & General Elective & Postural & São Paulo/Brazil \\
\hline Lee et al., 2014 & Minimally Invasive and Robotic & Postural and Mental & Baltimore/USA \\
\hline Aitchison et al., 2015 & Laparoscopy & Postural & Sydney/Australia \\
\hline Aghilinejad et al., 2016 & Open, laparoscopy and microsurgery & Postural & Tehran/Iran \\
\hline Ramakrishnan and Milam, 2017 & Functional Endoscopic Sinus Surgery & Postural & Colorado/USA \\
\hline
\end{tabular}

A variety of risk factors are involved in the occurrence of ergonomic constraints among surgeon's work, and According to Ramakrishnan and Milam, ${ }^{22}$ physical discomfort is one of that risks, resulting in some symptoms directly related to the performance in operating rooms. During Functional Endoscopic Sinus Surgery procedures, the authors found signs of physical fatigue amongst surgeons, which performed the operating room tasks in standing and sitting positions. The electromyography (EMG) measurements were able to demonstrate significant physical fatigue of different muscle groups in both positions.

The operating room is involved with a high-risk, dynamic and technologically advanced environment related to complex tasks took by multidisciplinary teams to deliver safe and effective treatment. Risks can be minimized by task management and ergonomic design of the operating room, as well as the use of effective patient pathways. It is also important to be careful with finding the best way of giving surgical skills training, team training, and with fulfilling World Health Organization checklists as well. Those requirements are important in maximizing productivity and safe delivery of care. ${ }^{5}$
Most of the researches done in Brazil and in the world deals with surgeon's physical and mental issues, without correlating them with the environmental conditions of the job. A survey on doctor's working conditions carried out by the Regional Council of Medicine of the State of São Paulo (CRMESP), for example, showed that medical practice in Brazil has migrated from the liberal exercise - where the doctor worked where he wanted, with the schedules and remuneration he determined - for practice within public and private bodies. The expansion of the Brazilian Unified Health System (SUS) and the expansion of the regulated segment of private health insurance plans intensified state and market's intervention mechanisms over the medical profession. Today, most doctors have public and private bonds, work overtime and accumulate jobs. The working hours of doctors are on average more than 50 hours a week and almost a third of the professionals work more than 60 hours. Doctors act on average in three different jobs, with more than $30 \%$ of them accumulating four or more workplaces, dividing the practice into the offices with receipt by self-production and with the generally employed work..$^{23}$

In general, Shouhed et al., ${ }^{4}$ affirm that the literature related to ergonomics and surgical practice has been growing gradually. For 
the authors, operating rooms are commonly intricate, high-stress environments, occupied by an enormous amount of equipment and technological tools, as well as an interdisciplinary staff. Operating rooms are contextually dynamic, with multi-skilled professionals with broadly different goals and training (empowerment) who have to work in a coordinated close mode. This complex context results in multiple opportunities for a poor communication process, a clash of motivations, the appearance of non-technological errors with cognitive influence, reduced interpersonal skills, and nonstandard environmental factors.

\section{Methods}

The present article involves a descriptive type of research. Moraes $\&$ Mont'Alvão ${ }^{24}$ point out that in this type of study, the researcher seeks to know and interpret reality without interfering to modify it. This approach is interested in discovering and observing phenomena and tries to describe, classify and interpret them. The problem will be stated in terms of whether a phenomenon happens or not, what variables constitute it, how to classify it, what differences or similarities exist between certain phenomena, etc. The data obtained - qualitative or quantitative - should be analyzed and interpreted. The authors also described a categorization and taxonomy for better identification of the ergonomic problems in the man-task-machine system.

The target system was characterized as hospitals " $A$ " and "B". Both are public University hospitals where high complexity procedures are performed. The hospital "A" has four surgical centers, 171 surgical clinic beds, attends to sixteen surgical specialties, has in its staff 173 surgeons, which from these, 86 work directly in the surgical centers. The Hospital "B" has 78 surgical beds, a staff of 57 surgeons and 15 doctors residing in surgery. The technical and physical area conditions of its surgical center are similar to those in hospital "A".

Data collection was performed between June 26 and August 10, 2014, through non-systematic observations and questionnaire application with closed questions (Figure 2).

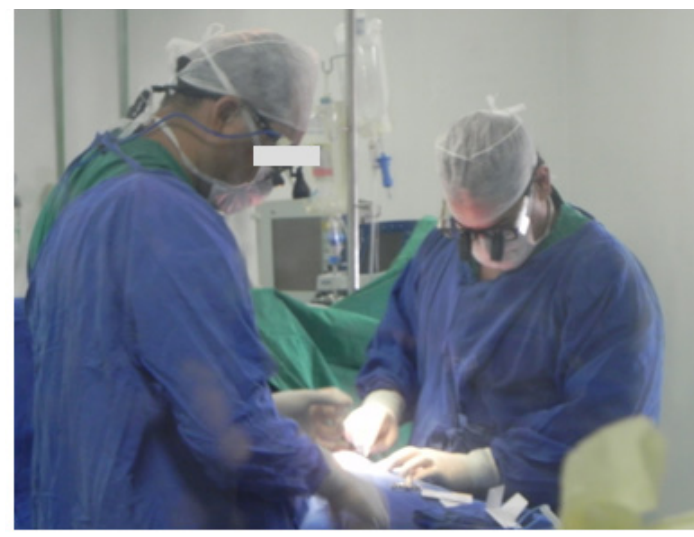

Figure 2 Surgeon's posture in Elective Surgery (Araújo, 20I4).

\section{Field observations}

Field book registrations and photographic records were used in the field observations. Six elective surgeries were observed in the morning, with two video laparoscopic cholecystectomies (Figure 3); a percutaneous nephrolithotomy; a microsurgery for intracranial tumor; an open thoracotomy; and total hip arthroplasty for prosthesis implantation. To choose the surgeries to be observed, the following criteria were used: the complexity to perform, the technology used and length of time. The field observations were based on the categorization and taxonomy of the ergonomic problems of the man- task-machine system proposed by Moraes \& Mont'Alvão. ${ }^{24}$ Five Ergonomic Demand Items (EDIs) from this categorization were used: 1. Physical/Environmental; 2. Spatial/Architectural; 3. Interfacial; 4. Psychosocial; 5. Organizational/ Management.

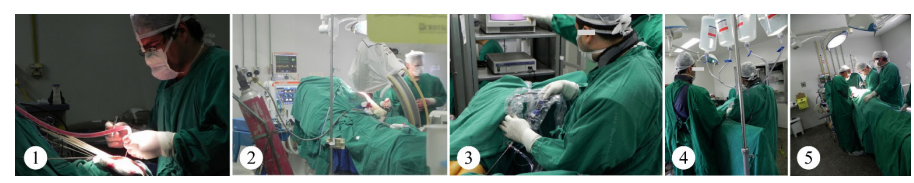

Figure 3 Examples of elective surgeries observed (I. Open thoracotomy surgery; 2. Microsurgery for intracranial tumor; 3. Total hip arthroplasty prosthesis implantation; 4. Video laparoscopic cholecystectomy; 5. Percutaneous Nephrolithotomy Surgery;).

\section{Questionnaire}

The questionnaire used was previously validated in a research carried out by Diniz, ${ }^{8}$ with adaptations regarding the number of questions. A pre-test was applied in which the level of understanding, the appropriate structure for the questionnaire and surgeons' availability in answering a number of questions were verified. It was then chosen to reduce it to 29 questions, evaluated by means of a continuous scale with two anchors at the edges (dissatisfied and satisfied) and an anchor at the center (neutral). This scale has a length of $15 \mathrm{~cm}$ and along with it, the respondent has marked his perception of the Ergonomic Demand Items (EDIs). The intensity of each response varied between 0 (zero) and 15 (fifteen). The name of the respondents was not requested, only personal data for profile composition (age, gender, manual dexterity, specialty and working time). The weight of the item is generated by its arithmetic mean. The same questionnaire was applied to staffs and residents. There were no returns of questionnaires, considering that responses were requested right after the presentation of the questionnaire.

The population found in the surgical centers of the two hospitals was 218 elements. For sample calculation a 5\% error was considered, a $95 \%$ confidence level for a finite population of 218 medical surgeons and an unknown percentage of ergonomic constraints, where a necessary sample of 140 elements was reached, totalizing a percentage of $64,22 \%$. The inclusion criteria were surgeons and resident doctors of surgical specialties who work directly in the surgical centers of the studied hospitals. The internal consistency of the questionnaire was evaluated by Cronbach's Alpha Coefficient test (Streiner, 2003). The Cronbach's alpha score was 0.8736 , showing a good internal consistency of the questionnaire used (Table 2). The research data were evaluated in the statistical program STATA version 12.0. (2011) and were tabulated considering the frequency of response, which was transcribed in percentages. The average, standard deviation and amplitude of the results were also obtained to demonstrate the homogeneity of the sample.

Table 2 Cronbach's Alpha Coefficient test for the questionnaire used

\begin{tabular}{llll}
\hline Questionnaire & $\begin{array}{l}\text { Elements } \\
\mathbf{N}^{\circ}\end{array}$ & Items $\mathbf{N}^{\circ}$ & $\begin{array}{l}\text { Cronbach's } \\
\text { Alpha Coefficient }\end{array}$ \\
\hline $\begin{array}{l}\text { Conditions } \\
\text { required at work }\end{array}$ & 140 & 17 & 0,8729 \\
$\begin{array}{l}\text { About work } \\
\text { environment }\end{array}$ & 140 & II & 0,8754 \\
\begin{tabular}{l} 
Total \\
\hline
\end{tabular} & 140 & 29 & $\mathbf{0 , 8 7 3 6}$ \\
\hline
\end{tabular}

\section{Ethical procedures}

The present research was approved by the FUMUH (University Teaching Hospital of Federal University of Maranhão), the Research 
Ethics Committee (CEP HU), in compliance with what is determined by the Resolution $n^{\circ} 492 / 96$ of the Brazilian National Health Council (CNS), in accordance with article 697.696. All who agreed to participate in the research signed the Free and Informed Consent Term (FICT).

\section{Results}

\section{Field observations}

The results of the non-systematic observations pointed to ergonomic constraints related to the Physical/Environmental and Organizational/Management categorizations, ${ }^{4,14,22}$ such as:

A. Insufficient space for people circulation and equipment allocation, which can cause accidents (Figure 4).

B. The absence of rational distribution of equipment's outlets and electrical cables inside the operating rooms (Figure 4).

C. Risk of accidents due to tumbling of people and equipment, besides electric shocks (Figure 4).

D. The absence of air conditioning in operating rooms, presenting only comfort cooling.

E. The absence of air conditioning in the arsenals of sterile material, compromising the sterility of the products stored there.

F. The absence of comfort cooling in critical and semi-critical areas of surgical centers, such as internal corridors and locker rooms.

G. The absence of reception and waiting rooms for patients in the preoperative period.

H. Occupancy of the post-anesthetic recovery room by preoperative patients.

I. The practice of parallel conversations and lack of regulation of equipment's sound signals.

J. Surgical tables' non-operating remote controls, making it difficult to position and move patients during surgery.

K. Poor general lighting in the environment, bringing discomfort and optical fatigue to the teams.

L. The racks where the video equipment used in the laparoscopes are arranged cause overload of muscular efforts during the surgical procedures since the surgeons must do rotation and cervical hyperextension to adjust the field of vision (Figure 5).

M. Absence of adjustable table for arm and adjustable padded swivel seat for use by vascular surgeons who operate seated (Figures 6\&7).

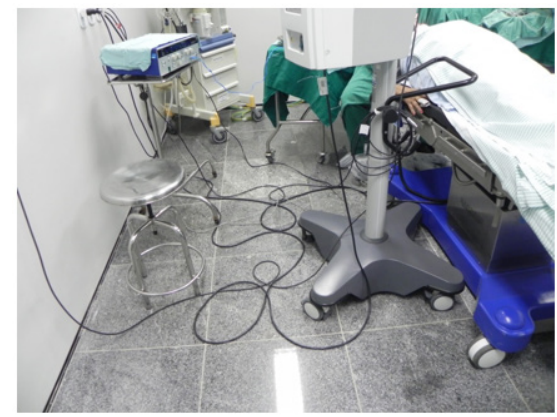

Figure 4 Spatial distribution of equipment.

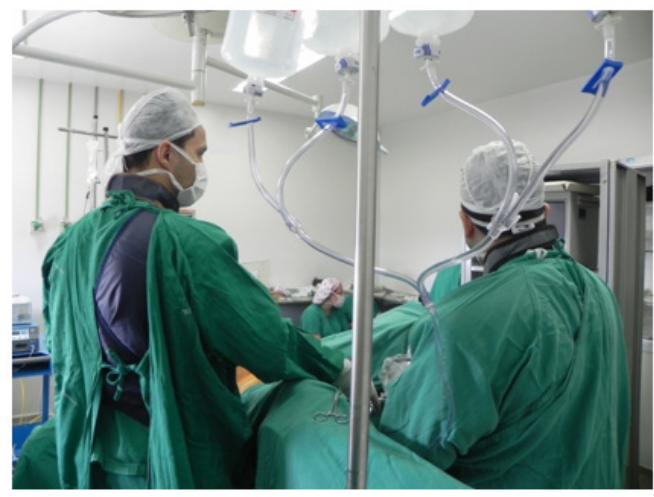

Figure 5 Surgeons executing rotation and cervical hyperextension to adjust the field of vision.

\section{Physical/ Environmental}

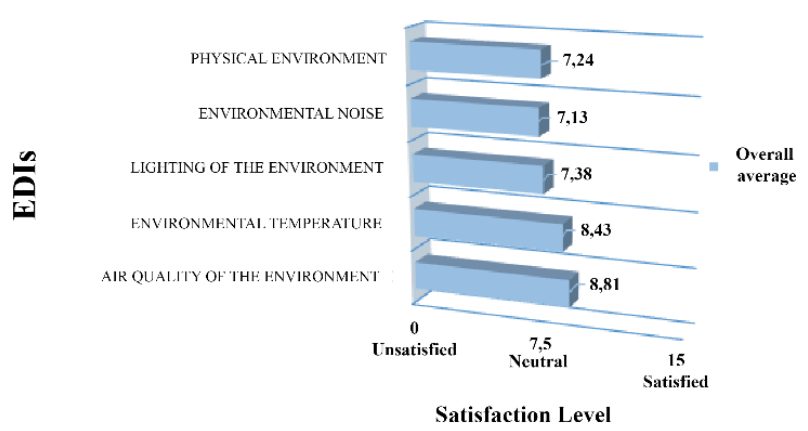

Figure 6 Cited EDls - Physical/Environmental.

\section{Psychosocial}

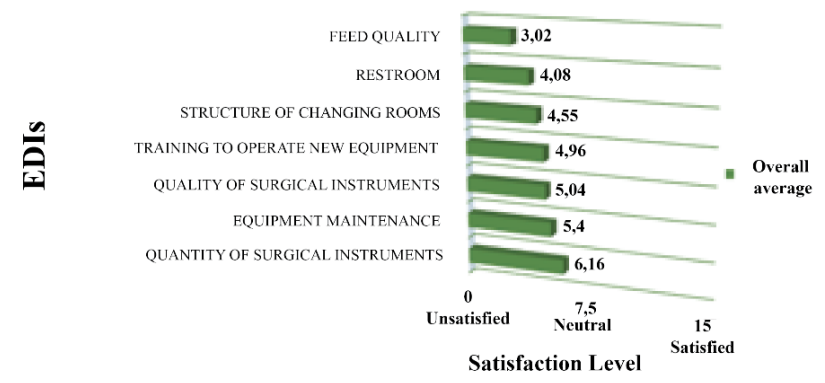

Figure 7 IEDs cited by the interviewees - Psychosocial.

\section{Questionnaire}

The minimum age found among the subjects of the research was 24 years and the maximum 72 years, with an average of 39.47 years, characterizing a young population; the predominant gender was male (77.86\%); the female $22 \%$; right-handers are $92 \%$; the regular practice of physical exercises is adopted by $37.14 \%$. A total of $25 \%$ do not practice exercises and $37.86 \%$ practice sometimes, showing that $62.86 \%$ of respondents do not have a regular practice of physical exercises (Table 3).

Regarding the surgical specialty, the respondents that were from general surgery correspond to $32.86 \%$, followed by gynecological obstetrics $(16.43 \%)$, urology $(12.14 \%)$, orthopedics $(10.71 \%)$, ophthalmology $(5.78 \%)$, cardiovascular and pediatric surgery (3.57\%), surgery of the digestive and vascular system $(2.86 \%$ each), plastic surgery, otorrino, mastology, thorax, plastic and neurosurgery ( $1.43 \%$ each), in addition to abdominal surgery, head and neck surgery and coloproctology, with $0.71 \%$ each (Table 4 ). 
Table 3 Physicians' characteristics

\begin{tabular}{|c|c|c|c|c|}
\hline Variables & Average & SD* & Min. & Max. \\
\hline Age & 39,47 & 12,39 & 24 & 72 \\
\hline \multirow[t]{2}{*}{ Working Time } & 11,97 & 12,38 & 0,25 & 46 \\
\hline & $\mathbf{n}$ & & $\%$ & \\
\hline \multicolumn{5}{|l|}{ Gender } \\
\hline Female & 31 & & 22,14 & \\
\hline Male & 109 & & 77,86 & \\
\hline \multicolumn{5}{|l|}{ Manual Dexterity } \\
\hline Left-handed & 9 & & 6,43 & \\
\hline Right-handed & 129 & & 92,14 & \\
\hline Ambidextrous & 2 & & 1,43 & \\
\hline \multicolumn{5}{|l|}{ Physical Activity } \\
\hline Practice regularly & 52 & & 37,14 & \\
\hline Practice sometimes & 53 & & 37,86 & \\
\hline \multirow[t]{2}{*}{ Does not practice } & 35 & & 25,00 & \\
\hline & 140 & & 100 & \\
\hline
\end{tabular}

*SD - standard deviation

Table 4 Physicians' specialties

\begin{tabular}{|c|c|c|}
\hline Specialties & $\mathbf{n}$ & $\%$ \\
\hline Digestive System Surgeon & 4 & 2,86 \\
\hline Cardiovascular Surgeon & 5 & 3,57 \\
\hline General Surgeon & 46 & 32,86 \\
\hline Abdominal Surgeon & 1 & $0,7 \mathrm{I}$ \\
\hline Pediatric Surgeon & 5 & 3,57 \\
\hline Plastic Surgeon & 2 & $\mathrm{I}, 43$ \\
\hline Thoracic Surgeon & 2 & $\mathrm{I}, 43$ \\
\hline Head and Neck Surgeon & 1 & $0,7 \mathrm{I}$ \\
\hline Vascular Surgeon & 4 & 2,86 \\
\hline Coloproctology & 1 & 0,71 \\
\hline Gynecology and Obstetrics & 23 & 16,43 \\
\hline Mastology - Oncologic Surgery & 2 & $\mathrm{I}, 43$ \\
\hline Neurosurgery & 2 & $\mathrm{I}, 43$ \\
\hline Ophthalmology & 8 & 5,78 \\
\hline Orthopedics & 15 & $|0,7|$ \\
\hline Otorrino & 2 & $\mathrm{I}, 43$ \\
\hline Urology & 17 & 12,14 \\
\hline Total & 140 & 100 \\
\hline
\end{tabular}

The Ergonomic Demand Items and their importance weights were identified through the questionnaire responses. The results are shown in the following figures. Regarding the problems categorized in the Physical/ Environmental item, also considering the scale of the questionnaire of 0 (not satisfied) and 15 (very satisfied), the EDIs for ambient noise $(7,13)$ and Lighting $(7,38)$ presented results below the Average of Satisfaction. The EDIs for room temperature (8.43) and air quality (8.81) were slightly above the Average of Satisfaction (Figure 8).

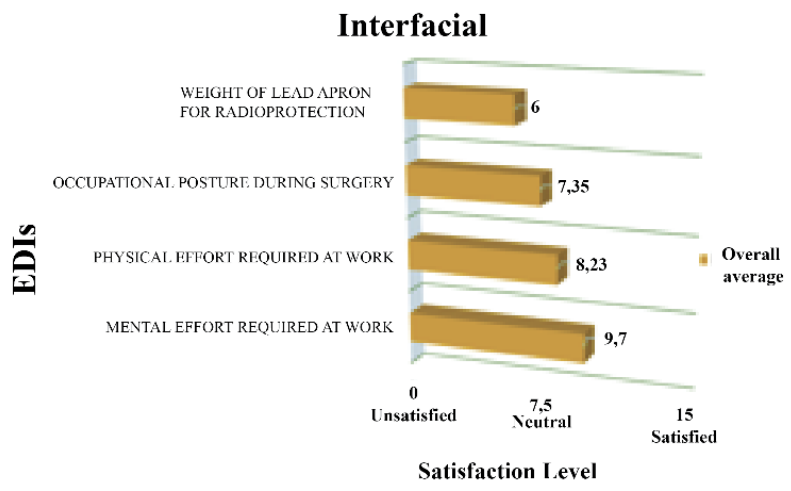

Figure 8 IEDs cited by interviewees - Interfacial.

The field observations corroborated these results. There was an absence of air conditioning in the operating room environments, with only comfort air conditioners in the surgery rooms from both hospitals, and there was the same absence of refrigeration in common areas like corridors, changing rooms, etc. The illuminance was not evaluated, but frequent requests for adjustment of the central light sources were observed, characterizing difficulties in the visual perception of the teams. Parallel conversations were also observed, as well as the noise produced by the equipment (anesthesia cars, monitors, etc.). The noise level has not been evaluated, but noise levels between 35 to 45 decibels are recommended for comfort in operating rooms. ${ }^{25}$ The responses to the EDI Architecture of the surgical center $(6,88)$ showed dissatisfaction of the respondents with incongruent arrangements, furniture and equipment arrangement, that give the environment a disorder and stressor aspect.

About the answers to the problems categorized in the Organizational/Managerial order, the IEDs Availability of employees to perform the work (3.69) and Management of the surgical center (5.83) showed dissatisfaction of the respondents in both questions, which compromises the quality of care provided to patients because of the workload imposed on professionals (Figure 9).

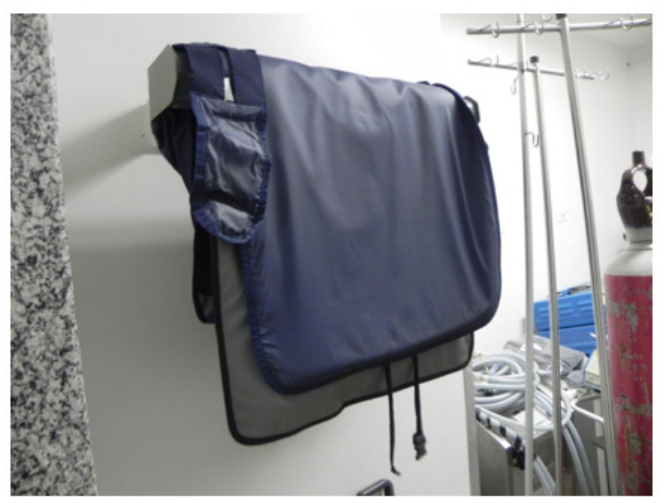

Figure 9 Lead apron and thyroid protection for radioprotection.

The responses to psychosocial IEDs revealed respondents' dissatisfaction with Food quality (3.02) and Suitable accommodations for resting (4.08), Structure of the changing rooms (4.55), Training to operate new equipment $(4,96)$, Quality of surgical instruments $(5,04)$, Maintenance of equipment $(5,4)$ and Quantity of surgical instruments 
$(6,16)$. The generalized dissatisfaction in this construct can lead professionals to an occupational stress condition.

This occupational stress can be a triggering factor for work-related illnesses, cause chronic reactions by the organism due to the daily threats of the situations experienced. The stressor agents can be related to physical or organizational environment. ${ }^{26}$ As for the interfacial IEDs (Figure 10), the weight of the lead apron for radioprotection (6.00) reveals dissatisfaction. The lead aprons and thyroid protectors that are used during radioscopy procedures have a weight of $5,100 \mathrm{~kg}$ in hospital A, varying from $4.9 \mathrm{~kg}$ to $7.0 \mathrm{~kg}$ in hospital B (Figure 11). During long-term surgeries, there were reports of pain/discomfort in the lumbar spine and shoulders by continued use of these aprons.

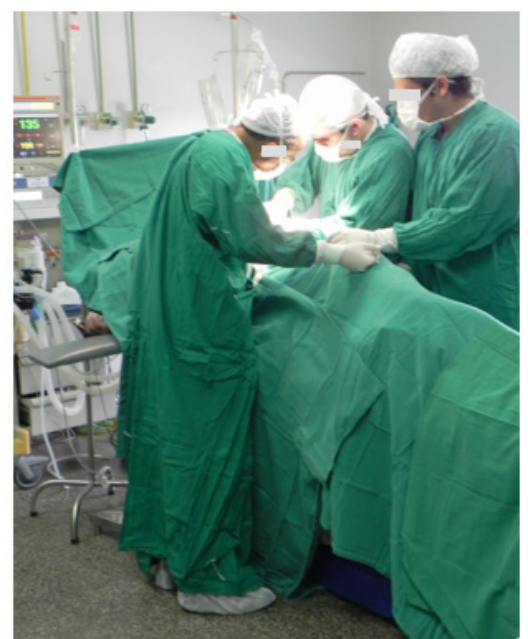

Figure 10 Occupational posture adopted in long-term surgery.

\section{LEVEL OF DISCOUNT / PAIN}

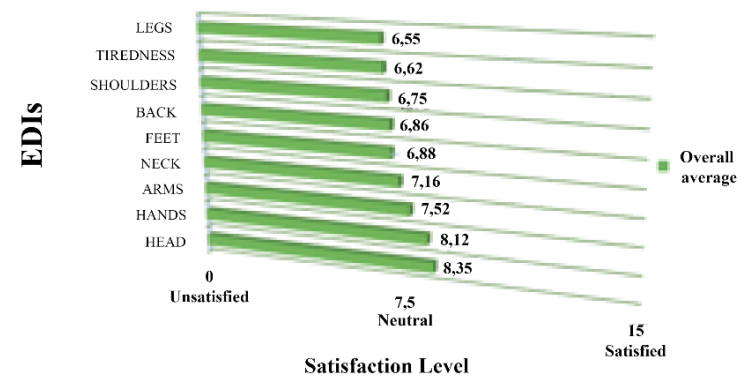

Figure I I Discomfort/pain levels.

In the responses to the IEDs Occupational posture during surgery $(7,35)$, Physical effort (8.23) and Mental effort required in their work $(9,70)$, they show that respondents perceive these IEDs as medium intensity ergonomic constraints. ${ }^{27-32}$

Regarding the perception of discomfort/pain levels, the results show that respondents perceived with dissatisfaction the presence of discomfort/pain for legs $(6,55)$, fatigue at the end of the workday (6.62), shoulders $(6.65)$, back $(6,86)$, feet $(6,88)$, neck $(7,16)$ and presented average levels for arms $(7,52)$, hands $(8,12)$ and head $(8,35) .^{5}$

\section{Discussions and conclusions}

The relevance of this work is to call attention to the existence of important ergonomic demands in the activities of a professional category whose functions have grave importance for society, dealing with the most valuable good, the human life. The problem is aggravated in university teaching hospitals, where besides the direct assistance to patients, there is also the presence of students who will become multipliers of the situations observed.

The difficulties experienced during data collection were related to access the information about the hospitals' management, such as amounts of professionals, quantities of surgeries performed, administrative processes, authorizations for photographic records, etc. Although they are public domain information, they are not easily available, due to the centralization in the hands of the administrators or even by not existing in an organized way.

The results show that in relation to the environmental and managerial issues directly involved with surgeons working conditions, (place of rest, structure of the changing rooms, maintenance of equipment, number of employees available to perform work, quality of food) the dissatisfaction level is worrying and short-term attention is needed, considering that the income, safety, satisfaction, as well as the result of the work of these professionals may be compromised as a result of their exposure to such problems.

Regarding the perception of discomfort/pain levels, the results show that respondents perceived with dissatisfaction the presence of this risk for almost all body segments surveyed, indicating the need for corrections to improve their health conditions.

It is concluded that there is much to be done to eradicate the ergonomic constraints that surround the surgeon and his workstation in the two researched institutions.

\section{Acknowledgments}

None.

\section{Conflicts of interest}

There are no financial conflicts of interest.

\section{Funding}

None.

\section{References}

1. Carayon P, Xie A, Kianfar S. Human factors and ergonomics as a patient safety practice. BMJ Qual Saf. 2013;0:1-10.

2. Carayon P, Wetterneck TB, Cartmill R, et al. Characterising the complexity of medication safety using a human factors approach:an observational study in two intensive care units. BMJ Qual Saf. 2014;23:56-65.

3. Berguer R. Surgery and Ergonomics. Arch Surg. 1999;134:1011-1016.

4. Shouhed D, Gewertz B, Wiegmann D, et al. Integrating Human Factors Research and Surgery:A REVIEW. Arch Surg. American Medical Association. 2012;147(12):1141-1146.

5. Bharathan R, Aggarwal R, Darzi A. Operating room of the future. Best Practice \& Research Clinical Obstetrics and Gynaecology. 2013;27:311322.

6. Berguer R. The application of ergonomics to general surgeon's working environment. Rev Environmental Health. 1997;12(2):99-106.

7. Zhu X, Yurteri-Kaplan LA, Cavuoto LA, et al. ErgoPART:A Computerized Observational Tool to Quantify Postural Loading in Real-Time During Surgery, IISE Transactions on Occupational Ergonomics and Human Factors. 2017;5(1):23-38.

8. Diniz RL. Assessment of the physical and mental demands on the surgeon's work in elective procedures [thesis]. Porto Alegre:Federal University of Rio Grande do Sul; 2003. 
9. Pradella D. The ergonomic characteristics and illness:the case of dentists in an association of service provision in Rio Grande do Sul [dissertation]. Novo Hamburgo:Feevale; 2012.

10. Sousa CS, Akamine J. Application of indicators for performance analysis of the surgical center. Rev Adm Saúde. 2008;10(41):147-150.

11. Gomes MCSMA. Organization and management of the surgical center of a University Hospital from Belo Horizonte - Minas Gerais. Belo Horizonte:Federal University of Minas Gerais; 2009.

12. Matos DGO. Work of the Surgical Center Nurse:a study from the perspective of Ergonomics [thesis]. Brasília:University of Brasília;1994.

13. Duarte AF, Souza APC, Macedo AF, et al. Risk factors for work-related musculoskeletal disorders - WRMD in nursing professionals. Revista de Pesquisa:Care is Fundamental Online. 2012;(Ed. Suppl):53-56.

14. Matern U, Koneczny S. Safety, hazards and ergonomics in the operating room. Surg Endosc. 2007;21:1965-1969.

15. van Det MJ, Meijerink WJ, Hoff C, Totté ER, Pierie JP. Optimal ergonomics for laparoscopic surgery in minimally invasive surgery suites:a review and guidelines. Surg Endosc. 2009;23(6):1279-1285.

16. Szeto GPY, Ho P, Ting ACW, et al. Work-related musculoskeletal symptoms in surgeons. J Occup Rehabil. 2009;19:175-184.

17. Xiao DJ, Jakimowicz JJ, Albayrak A, et al. Ergonomic factors on task performance in laparoscopic surgery training. Applied Ergonomics. 2012;43(3):548-553

18. Esposito C, El Ghoneimi A, Yamataka A, et al. Work-related upper limb musculoskeletal disorders in pediatric laparoscopic surgery. A multicenter survey. Journal of Pediatric Surgery. 2013;48(8):1750-1756.

19. Lee GI, Lee MR, Clanton T, et al. Comparative assessment of physical and cognitive ergonomics associated with robotic and traditional laparoscopic surgeries. Springer Science+Business Media New York 2013. Surg Endosc. 2014;28:456-465.

20. Aitchison LP, Flint J, Nesbitt-Hawes E, A Feasibility Study Determining Surgical Ergonomics in a Live Surgical Setting. Journal of Minimally Invasive Gynecology. 2015;22(4):626-630.
21. Aghilinejad M, Ehsani A, Talebi A, et al. Ergonomic risk factors and musculoskeletal symptoms in surgeons with three types of surgery:open, laparoscopic, and microsurgery. Med J Islam Repub Iran. 2016;30:467.

22. Ramakrishnan V, Milam B. Ergonomic analysis of the surgical position in functional endoscopic sinus surgery. International Forum of Allergy \& Rhinology. 2017;7(6):570-575.

23. Scheffer M, Biancarelli A, Cassenote A, et al. Medical Demography in Brazil:general data and descriptions of inequalities. São Paulo:Regional Council of Medicine of the State of São Paulo and Federal Council of Medicine;2011.

24. Moraes A, Mont'Alvão C. Ergonomics:concepts and applications. 4th ed. Rio de Janeiro. 2AB;2012.

25. ABNT - Brazilian Association of Technical Standards. NBR 10152:noise levels for acoustic comfort. Rio de Janeiro:ABNT; 1987.

26. Lacaz FAC. Quality of life at work:a political and polysemic concept. Trabalho, Educação e Saúde. 2009;7(3):565-572.

27. Szeto GP, Ho P, Ting AC, et al. A study of surgeons' postural muscle activity during open, and laparoscopic, and endovascular surgery. Surg Endosc. 2010;24(17):1712-1721.

28. Abdalla RZ, Averbach M, Ribeiro-Junior U, et al. Abdominal surgery by robotics:Brazilian initial experience. $A B C D$, arqbrascir dig. 2013;26(3):190-194.

29. Araújo FM. Evaluation of the working conditions of the surgeon in public procedures in São Luís [dissertation]. São Luís; Federal University of Maranhão; 2014.

30. Foss MHD, Martins MRI, Bozola, AR. Postural changes in surgeons caused by the professional activity. Brazilian Journal of Plastic Surgery. 2012;27(2):195-200.

31. StataCorp. Stata version 12.0. 2011

32. Streiner DL. Being inconsistent about consistency:when coefficient alpha does and doesn't matter. Journal of Personality Assessment. 2003;80:217222. 